Synthesis, vol. 24, $\mathrm{n}^{\mathrm{o}}$ 1, e015, junio 2017. ISSN 1851-779X

Universidad Nacional de La Plata.

Facultad de Humanidades y Ciencias de la Educación.

Centro de Estudios Helénicos

\title{
La voz y el movimiento de la voz en la teoría musical griega antigua y tardoantigua: Nicómaco de Gerasa y Gaudencio el Filósofo
}

\section{Fuensanta Garrido Domené *}

* Universidad de Huelva, España

\section{PALABRAS CLAVE}

Música griega antigua

Movimiento de la voz

Nicómaco de Gerasa

Gaudencio el filósofo

\section{KEYWORDS}

Ancient Greek Music

Motion of the Voice

Nicomachus of Gerasa

Gaudentius the Philosopher

\section{RESUMEN}

Este trabajo está basado en la atenta lectura, traducción y análisis de las obras harmónicas de Nicómaco de Gerasa y de Gaudencio el Filósofo. Estos autores son considerados paradigmas de una concepción pitagórica y ecléctica de la música griega antigua y tardoantigua, respectivamente. En él, se subrayará la importancia de la voz como elemento de la Harmónica y se expondrán sus movimientos y clasificación. $\underline{1}$
ABSTRACT
This paper is based on the careful reading, translation and analysis of Nicomachus of Gerasa's and Gaudentius the Philosopher's harmonic works. These authors are considered paradigms of a Pythagorean and eclectic understanding of the ancient Greek music and the music from Late Antiquity, respectively. In it, the importance of the voice like an element of Harmony will be emphasised and its motions and classification will be presented.

Cita sugerida: Garrido Domené, F. (2017). La voz y el movimiento de la voz en la teoría musical griega antigua y tardoantigua: Nicómaco de Gerasa y Gaudencio el Filósofo. Synthesis, 24(1), e015. https://doi.org/10.24215/1851 $\underline{779 \mathrm{Xe} 015}$ 
Tomando como punto de partida el hecho de que la música, en su sentido más amplio, es una propiedad inherente a la naturaleza -hablamos del canto de las ballenas, de los delfines, de los pájaros, del graznido de ciertas aves o del aullido de los lobos-, en la esfera humana la música y su arte ha sido, desde tiempos ancestrales, un aspecto tenido muy presente en la vida del individuo y de las sociedades. Sin embargo, la cuestión de qué fue antes, si la música o la palabra, sigue dividiendo a la crítica. La Antropología hace presuponer que incluso antes de que el hombre fabricase instrumentos musicales ya hacía música cantando, batiendo palmas o golpeando objetos, demostrando, así, la íntima relación entre la especie humana y este arte. Con todo, no faltan quienes postulan que, mientras que algunas interpretaciones tradicionales vinculaban el surgimiento de la música a actividades intelectuales relacionadas con el concepto de lo sobrenatural (desempeñando una función de finalidad supersticiosa, mágica o religiosa), actualmente se relaciona con los rituales de apareamiento y con el trabajo colectivo. Al no emplear instrumentos musicales en su origen para interpretarla, sino la voz humana o la percusión corporal -que no dejan huella en el registro arqueológico-, puede inferirse que la música se descubrió en un momento similar al de la aparición del lenguaje. Del mismo modo, el que el cambio de altura musical en el lenguaje pudiera producir un canto invita a pensar en la posibilidad de que en sus orígenes apareciera de esta manera. Es decir, la música nació al prolongar y elevar los sonidos del lenguaje. Sea como fuere, también es un hecho aceptado que en casi todas las culturas la música es tenida como un regalo de los dioses, una imitatio sonorum entre los hombres que no cantan, sino hablan. $\underline{\underline{2}}$

Esta herencia de la naturaleza tomada, quizá, por instinto fue evolucionando hasta alcanzar cierta regularización por parte del hombre, culminando en una consideración de música como materia digna de ser estudiada. En este sentido, ya la antigua Grecia la incluyó entre sus disciplinas, llegando a teorizar sus elementos y sus modelos de prácticas. Poco a poco, la ноuбikń -propiamente "el arte de las Musas”- se fue desarrollando hasta convertirse en

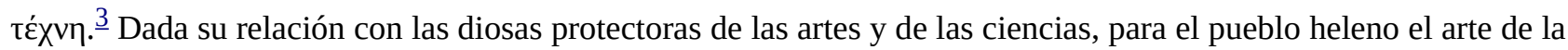
Música encerraba en sí un vastísimo concepto de cualidades espirituales y artísticas, especialmente aquellas vinculadas con la poesía lírica. A partir del siglo IV a. C. se empezó a emplear el término música en su sentido

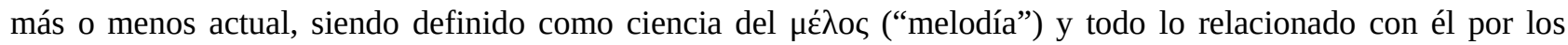
musicógrafos posteriores. $\stackrel{4}{ }$ Anterior a esta época, únicamente las formas relacionadas con la música instrumental y/o práctica eran las propias para referirse a esta ciencia. En su sentido puramente musical, el arte de las Musas comprende dos partes: la teórica y la práctica o educacional. En el presente trabajo nos dedicaremos a la primera, prestando especial atención a la categoría de la voz. $\underline{\underline{5}}$

Muchos de los tratados que la tradición ha conservado incluyen en sus páginas un tratamiento más o menos similar de esta categoría tenida como tradicional ya desde la época de Aristóxeno de Tarento: la voz y su movimiento. De ellos, tomaremos como base de nuestro análisis los manuales de Nicómaco de Gerasa y de Gaudencio el Filósofo: éste es musicólogo de la Antigüedad tardía (sito en algún momento entre el siglo II y V d. C.) y paradigma de autor ecléctico, si bien en el capítulo de su Manual de harmónica dedicado a la voz se muestra como seguidor de la escuela aristoxénica; aquél es un músico y matemático del final del siglo I a. C. y la primera mitad del siglo I d. C., fiel, por tanto, a la doctrina promulgada por Pitágoras de Samos y declarado enemigo de la escuela aristoxénica. $\underline{6}$ 


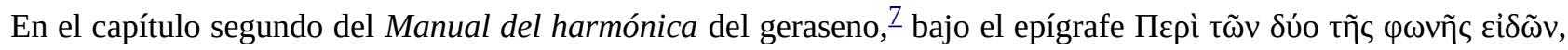

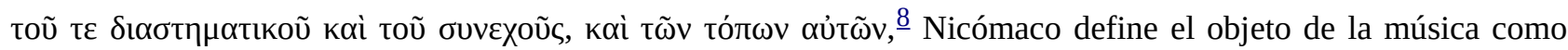
ciencia de la voz discontinua, esto es, cuantitativamente determinable. Pese a salirse de los cánones de composición seguidos por la mayoría de téoricos posteriores a Aristóxeno de Tarento, $\underline{9}$ sí que se ajusta a esta tradición en su intento por establecer la diferencia entre expresión musical y hablada. Así, cuando Nicómaco se comprometió a componer este escrito, $\underline{10}$ su explicación científica siguió la convención aristoxénica ya establecida que se basaba en los principios de movimiento vocal y espacio melódico. Sin embargo, este musicólogo fue más lejos que ningún otro al atribuir el concepto de movimiento y los tipos de voz a los pitagóricos y al ignorar al tarentino.

En este capítulo, luego de atribuir a los pitagóricos la diferencia entre voz continua e interválica y de explicar sendas denominaciones, Nicómaco pasa a describir cada una de ellas para abordar las cuestiones de sus regiones y de lo que podríamos llamar “umbrales de sonido”, aplazando la cuestión del origen de la emisión de sonido.

Gaudencio, por su parte, tras definir en el primer capítulo de su tratado la región de la voz y sus categorías consecuencia última de su movimiento-, se ocupa de cada una de ellas, id est, de la voz hablada y de la interválica, así como del canto melódico y no melódico -en cuanto a modos de ejecución de ésta-, para concluir con la diferencia entre tensión y distensión. Otra interpretación de la estructura del pasaje saca a la luz el tratamiento de lo que podrían considerarse dos principios quasi naturales de la voz: тóтоৎ у кívпбıs, esto es, “posición” o “lugar” (incluso “extensión”), y “movimiento”.11 Así, aunque la descripción gaudentiana de región de la voz resulta demasiado parca y no del todo literal a la que parece remitirse, $\underline{12}$ es completada con la que cierra

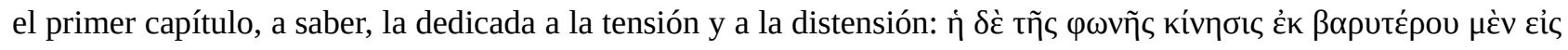

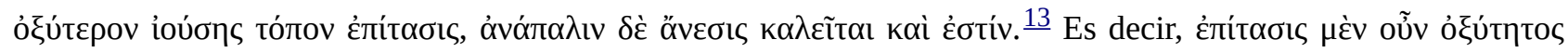

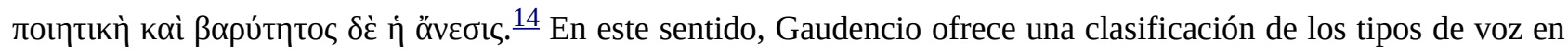
virtud del cambio de posición que ésta pueda sufrir. $\underline{15}$

Que hay dos tipos de voz humana, una continua y otra interválica, es una afirmación que pertenece no a los pitagóricos, como intenta hacer creer Nicómaco, sino a Aristóxeno de Tarento. Aunque la fuente principal para todo el pasaje es el tarentino, lo que muestra claramente el lenguaje empleado por el autor, $\underline{16}$ aquél no es reconocido como tal por éste. Esta falta de mención del músico de Tarento ha llevado a la crítica a postular diversos puntos de vista, aunque cercanos unos de otros. ${ }^{17}$

En un principio, para Nicómaco existen dos tipos de voz humana: la interválica y la continua. La interválica es calificada por el geraseno como "musical” ( (voz) que se emplea en el canto" o, incluso, "para el canto”, de ahí que sea "melódica” o, en términos más generales, "musical”. Aunque en la primera parte de la definición parafrasea claramente a Aristóxeno, $\underline{18}$ aun sin reconocerlo, en la segunda su exposición adquiere tintes pitagóricos, donde las notas participan en y del tamaño del intervalo al que están vinculadas, situadas unas junto a otras, no conformando el continuum lineal aristoxénico del tono. $\frac{19}{}$ Así, esta tipología de voz -según Nicómaco- es la que hace evidente la variación de sonido; sin

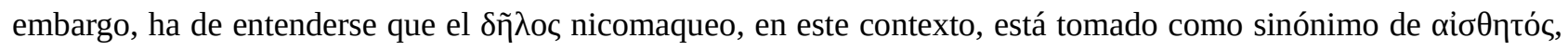

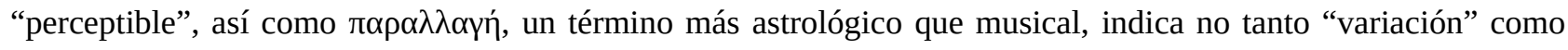
“movimiento alterno". De esta suerte, Nicómaco resalta por encima de todo la suma de valores ( $\sigma \omega \rho \varepsilon i ́ \alpha)$ distintos

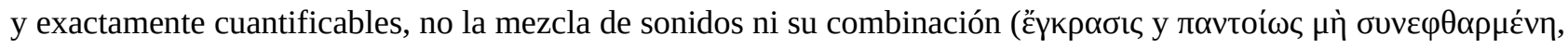
respectivamente). $\underline{\underline{20}}$ Tal atención, por parte del geraseno, difiere de la del tarentino, quien, a la hora de describir el fenómeno, hace énfasis en el tipo de movimiento.

Gaudencio también distingue dos tipos de movimiento empleando una terminología que recuerda a Aristóxeno: $\underline{21}$ el propio de la palabra, es decir, el movimiento del habla (入оүıкń), y el separado por intervalos o interválico, o 


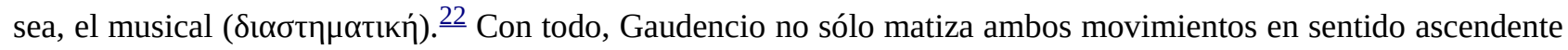

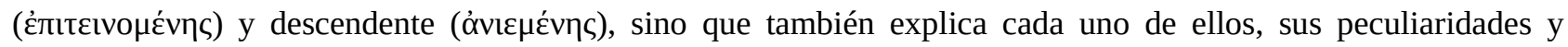
aplicaciones, describiendo la diferencia entre el proceso del habla (દ่v

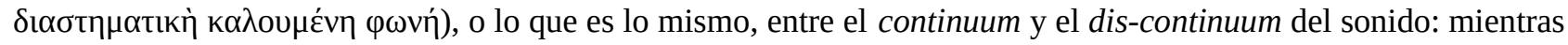

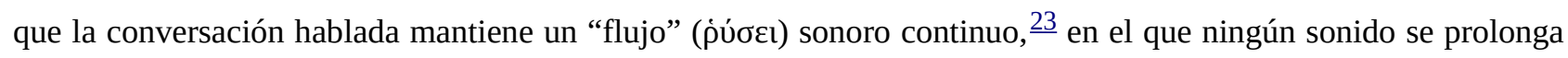
de forma permanente ni existen saltos sonoros perceptibles, modulando, por tanto, el habla dentro de la región de la voz comprendida entre el registro más grave y el más agudo, por su parte el canto, aun conservando su discurrir sonoro en el tiempo, manifiesta una discontinuidad en cuanto al sonido, pues no produce sonidos continuos entre ellos, sino que se basa más en la entonación de una determinada nota para saltar a continuación, y sin ser conscientes de ello, a otra dentro de un intervalo concreto y determinado. ${ }^{24}$ En definitiva, la voz interválica fue llamada con razón así, por oposición a la hablada.

Las expresiones y los adjetivos con los que Nicómaco, en cambio, califica la voz llamada interválica o discontinua -por oposición a la continua-, parecen igualmente propios de él: ảoúYxutov (“libre de confusión”),

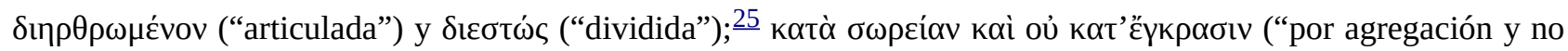

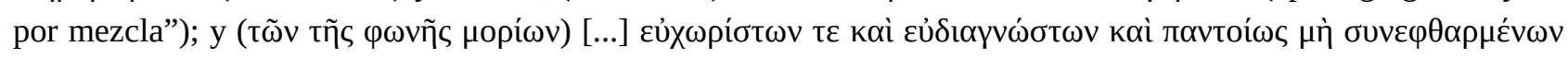
(“[de las partes de la voz]... siendo éstas fáciles de separar y de distinguir y, de ninguna manera, combinadas unas con otras”).

La llamada voz interválica presenta, en Gaudencio, la propiedad y/o particularidad de la doble modalidad de

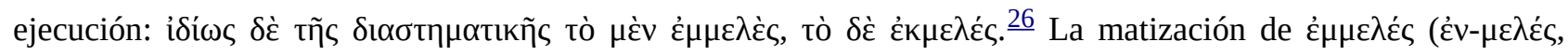

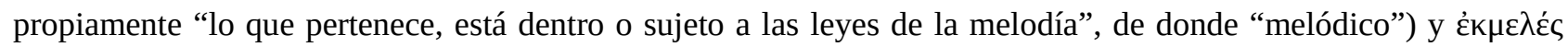
( $\dot{\kappa}$ - $\mu \varepsilon \lambda \dot{\varepsilon} \varsigma$, "lo que queda fuera, no pertenece o es contrario a las leyes de la melodía”, de donde "no melódico") referido al $\mu \varepsilon ́ \lambda$ os pertenece, una vez más, al ámbito de la terminología aristoxénica. $\stackrel{27}{E}$ El melólico hace uso de

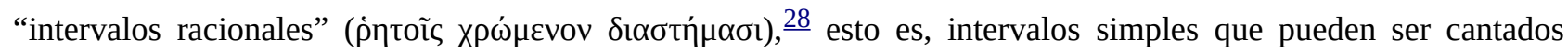
porque suenan bien al oído y son, por ello, justos, $\underline{29}$ noción contraria -que no concepción- a la defendida por los pitagóricos, quienes únicamente se basaban en relaciones numéricas. Sin embargo, tales intervalos, tanto racionales entre sí como con otros, presentan un principio de conmensurabilidad, en cuanto que admiten una melodía común y concerniente a los números, o sea, cuantitativa. $\underline{30}$ Por lo tanto, el condicionante para que haya canto melódico radica en la exactitud de los intervalos, pues no deben estar en defecto ni en exceso respecto a los intervalos determinados por la constitución de las escalas melódicas. En caso contrario, el canto será no melódico.

Con un estilo y un timbre típicamente aristoxénicos, $\underline{31}$ la descripción de la voz continua por parte de Nicómaco viene a complementar, en cuanto a su opuesto, a la anterior. Se trata de la voz hablada, propia de la conversación común, donde no es necesario manifestar diferencias entre los grados de las notas ya que, únicamente, se pronuncian las palabras, una tras otra, hasta complementar la frase.

Los dos condicionantes para que, en opinión de Nicómaco, se dé una u otra voz recuerdan, asimismo, el pensamiento aristoxénico y su exposición. Sin embargo, la crítica ha querido ver en la segunda de ellas la referencia, consideración o, al menos, conocimiento de nuestro autor del llamado "tercer tipo intermedio". $\underline{32} \mathrm{El}$

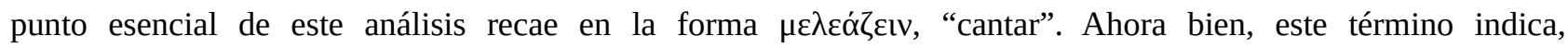
propiamente, "hablar o leer con una cierta ondulación musical de la voz" y puede ser interpretado con el significado "entre hablar y cantar", como el recitativo parlando, voz italiana que en el ámbito musical se refiere a

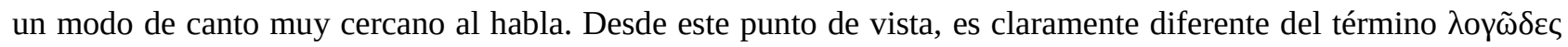
$\mu \varepsilon \dot{\lambda}$ os de Aristóxeno, $\underline{\underline{3}}$ esto es, “melodía conversacional”, pero, al mismo tiempo, parece referirse al tercer tipo de movimiento vocal del que ya habló Arístides Quintiliano y que, según él, se usaba en las declamaciones poéticas. $\underline{34}$

Este tercer tipo en el que se mezclan y/o se combinan canto y habla parece convertirse casi en un tópico, 
reapareciendo en musicógrafos posteriores, como en el ya mencionado, en Arístides Quintiliano, en Baquio Geronte, en el texto de los Anónimos de Bellermann, $\underline{35}$ en Boecio, $\underline{36}$ quien atribuye la consideración de esta categoría de voz a un tal Albino, e incluso en Marciano Capela. $\underline{37}$ Para todos ellos, esta clase de melodía vocal es una especie en sí misma. Por el contrario, en opinión de Luisa Zanoncelli, la alusión por parte de Nicómaco a esta voz recitativa no tiene sino una intención polémica. $\underline{38}$

Así, aunque Nicómaco no lo dice, el término general en el que están incluidas las dos especies de voz humana es

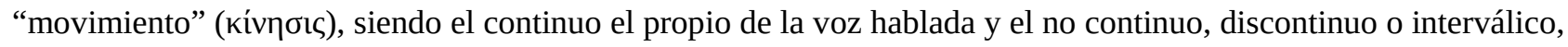
el propio de la voz cantada. He aquí uno de los grandes objetivos de los antiguos teóricos musicales: distinguir

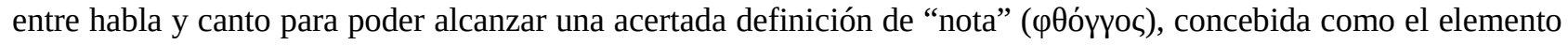
indivisible más pequeño en la percepción auditiva. El estudio, por tanto, de los sonidos con métodos exclusivamente matemáticos es muy difícil y abstracto. Estamos de acuerdo con Flora Rose Levin al contemplar que es éste un concepto base del pensamiento aristotélico, donde nociones como la de número, peso o medida no comportan significado filosófico alguno. $\underline{\underline{39}}$ Ha de considerarse en este sentido que Aristóteles es más físico que matemático, por lo que su estudio se centra en el movimiento en sí, sin intentar definirlo mediante el número. Según él, a la hora de abordar la cuestión de la kívnoıs hay que tener presentes dos partes: la cinemática o estudio

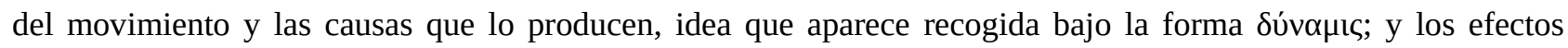

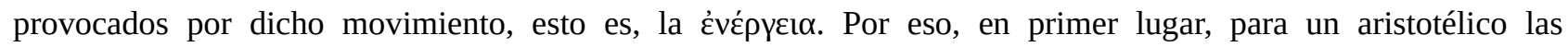
matemáticas nunca pueden estudiar el movimiento, ya que debe realizar una abstracción enorme; $\underline{40}$ en segundo lugar, el movimiento del sonido no es material (locomotriz), ni se puede observar directamente, por lo que, en conclusión, mediante las matemáticas no se puede llegar a entender de sonidos o de música. En definitiva, el movimiento que define Nicómaco es similar, al menos en apariencia, al movimiento físico aristotélico y, como tal, pertenece a un espacio o continuum de tipo cualitativo, donde cada tono tiene su lugar melódico y su función propia.

A partir de aquellas definiciones, Nicómaco establece los límites o regiones de cada tipo de voz. La voz continua carece de límites en su magnitud, dado que depende tan sólo de la persona que habla, única responsable que decide cuándo comienza y cuándo termina el acto de hablar. Sin embargo, la voz interválica está sometida a la naturaleza, limitando su campo al intervalo existente entre aquellos sonidos que pueden ser emitidos y aquéllos

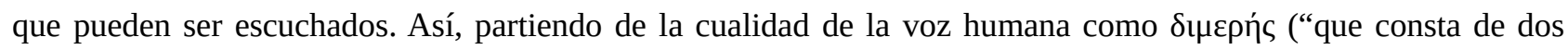
partes”), $\underline{\underline{4}}$ el eje en el que se centra la cuestión de los espacios de la voz es la preocupación por la limitación o no limitación de ésta o, dicho de otro modo, por la naturaleza finita o infinita de ambos tótoo. Semejante interés parece tener, de nuevo, origen aristotélico, $\frac{42}{}$ si bien es cierto que Platón ya abordó la discusión sobre lo uno y lo múltiple. $\underline{43}$

Aplicado al fenómeno de la música, en dicho tóтоৎ la voz únicamente tiene dos direcciones posibles: hacia arriba y hacia abajo, $\underline{44}$ pero para un aristotélico hay más movimientos que implican innumerables maneras de efectuar cambios de cualidad y aspecto. Sus límites para Aristóteles, Aristóxeno -cuya teoría musical es inequívocamente aristotélica- y Nicómaco están definidos por lo que la voz puede hacer y el oído captar, tanto en tono como en volumen, id est, por los registros de la voz y la capacidad de conseguir mayor o menor volumen, por un lado, y por la capacidad del oído humano de percibir ese sonido. Concretamente para Nicómaco, ese espacio melódico es puramente matemático, de ahí que, tomado en su conjunto, forme las coordenadas del universo pitagóricoplatónico que puede ser medible de forma matemática. $\frac{45}{4}$

Sea como fuere, las palabras de Nicómaco evocan aquéllas de Aristóxeno con las que éste también habla

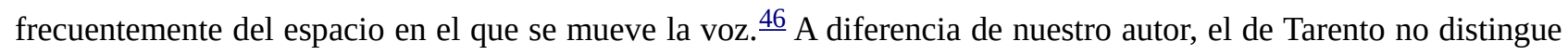
dichos tómol, pues, a su entender, únicamente existe uno, el de la dimensión del tono, donde sendos movimientos vocales, el interválico o discontinuo y el continuo, se realizan aunque de diferente manera. Con esta comparación 
como fundamento, Andrew Barker estima la poca clarividencia de la exposición y concepción de Nicómaco al respecto o, si acaso, su simplicidad al reducir los límites espaciales de una y otra voz a una diferencia intermedia. $\stackrel{47}{ }$ Sin embargo, al haber sido Aristóxeno el primero en diferenciar entre movimiento continuo y movimiento interválico, $\underline{48}$ convendría precisar la concepción de movimiento y espacio para un aristoxénico y para un pitagórico. Mientras que para éste el movimiento es la causa medible y observable -esto es, perceptible- del sonido (agudo y grave), para aquél es la realización de todo lo que potencialmente está en la voz, ya sea tono, volumen o matices. De igual manera, espacio en sentido pitagórico no es sino la dimensión medible, absoluta, invariable y sujeta a las leyes matemáticas, pero en sentido aristoxénico indica el continuum (variable) delimitado por la propia voz y sus posibilidades.

De cualquier manera, la repetición de las palabras y concepciones aristoxénicas se hallan en la precisión pitagórica del límite de la región de la voz continua. $\frac{49}{}$ Ésta, como dice Nicómaco, depende de nosotros, pues es la que comporta, de alguna manera, el acto del habla. Su ilimitación, por tanto, atañe a la duración y altura de cada nota o sonido emitido, cuya elección depende exclusivamente del hablante. Así, según Porfirio, sólo es posible establecer la duración total de la emisión o palabra emitida, en tanto que no ha lugar a valores capaces de sufrir una medida exacta. $\underline{50}$

Por otra parte, los diversos efectos, operaciones o causas, responsables últimos de la limitación de la región de la voz interválica, son los que impone la propia naturaleza. Sin embargo, para Andrew Barker dicha naturaleza no puede ser la del movimiento discontinuo concebido abstractamente, pues sería decir que depende de nuestras facultades de audición y emisión. $\underline{51}$ Por eso, Barker precisa que las palabras de Nicómaco en este sentido han de tomarse no como que "no depende de nosotros", sino del "capricho individual". $\underline{\underline{2}}$ No estamos del todo de acuerdo con la postura de Barker, pues no interpretamos غ̇ $\varphi^{\prime} \eta \dot{n} \mu \mathrm{v}$ como una “dependencia incontrolada” que podría implicar aquel "capricho individual”, sino, más bien, un apego, una regulación o, incluso, un sometimiento, al

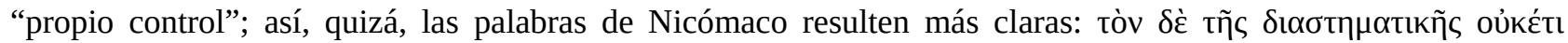

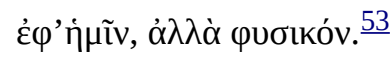

En términos generales, pues, el punto de partida y el punto final nicomaqueo es paralelo a la opinión de Aristóxeno del intervalo más pequeño y más grande que se puede usar. ${ }^{54}$ Pese a ello, Nicómaco no está hablando aquí de intervalos, ni siquiera de tonos, sino de nuestra consciencia y capacidad de discriminación de "magnitudes

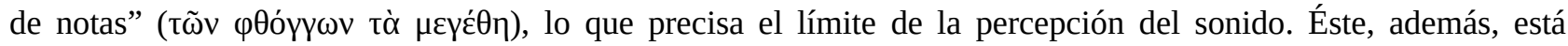
determinado por el primer estímulo recibido en nuestro oído, en tanto que existen en la naturaleza sonidos que no pueden ser percibidos. El geraseno se basa, para una afirmación tal, en la intensidad del sonido, de forma que nuestro órgano auditivo no es capaz de percibir sonidos muy débiles. Así, al igual que la paja no puede desnivelar una balanza, aunque su acumulación puede tener una masa suficiente como para conseguir tal desnivel, de forma análoga un sonido muy débil no es perceptible, mientras que su acumulación sí puede llegar a serlo. Dicha afirmación no está exenta de razón, ya que hoy día se sabe que la audición no sólo depende de la intensidad del sonido, sino de las características físicas del mismo (entre otras, longitud de onda y frecuencia); de hecho, cada especie animal tiene diseñado su aparato auditivo para captar un determinado radio de sonidos. Piénsese, por ejemplo, en aquellos animales que pueden captar sonidos de menor frecuencia que un humano, como los generados por fenómenos telúricos. $\underline{55}$

De cualquier manera, Nicómaco se está refiriendo concretamente a la debilidad de un sonido y es muy probable, como apunta Andrew Barker, $\underline{56}$ que en estas líneas aluda de manera velada al tono y al volumen. $\underline{57}$ Así, los sonidos más débiles a los que se refiere Nicómaco son, ciertamente, los sonidos graduados más bajos que se pueden usar melódicamente.

De forma parecida a la anterior, asegura que el primero de los límites del sonido -el de emisión- está determinado por la voz, pues, a partir de un volumen mínimo, conforme va aumentando gradualmente, el sonido siempre es 
perceptible, estando definido su nivel máximo por la capacidad del foco emisor.

Hoy día, en contra de lo que dice Nicómaco, sabemos que el oído humano también tiene un límite superior de percepción a partir del cual se daña, dejando de percibir sonido alguno. Estos límites son conocidos como "umbrales del sonido”: el umbral de percepción o de audición es el nivel mínimo en el que un sonido es percibido, mientras que el umbral de dolor es el nivel máximo sonoro al que nuestros órganos auditivos pueden estar expuestos (aproximadamente 120 decibelios) y por encima del cual éstos pueden dañarse.

El tratamiento gaudentiano al final del primer capítulo de Introducción a la harmónica no dista mucho, de facto,

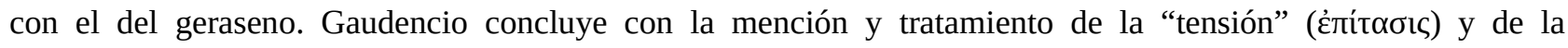

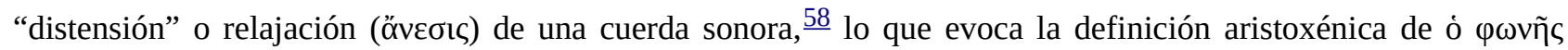
то́тоৎ, al tiempo que se mantiene fiel a una larga tradición de teoría musical que toma como punto base las definiciones aristóxenicas de los elementos de la Harmónica. $\underline{59}$

Así, en la descripción del fenómeno tensión-distensión, responsables últimos de la agudeza o gravedad de una nota, subyace una relación biunívoca, en sentido de causa-efecto, pues no sólo queda patente y demostrado que al tensar una cuerda la nota emitida es más aguda, sino que, al cesar y detenerse el aumento de dicha tensión y permanecer fija, la agudeza emitida se mantiene. De ahí que la tensión afecte a la agudeza y a la gravedad por igual, dado que en ambas se produce cierta tensión, en tanto que una cuerda que carezca de ella no emite sonido alguno.

En conclusión, se ha demostrado en estas páginas que la tradición tardía en materia musical hereda, veladamente, las consideraciones de Aristóxeno de Tarento pese a la manifiesta oposición de ciertos musicólogos, con la salvedad de la novedosa consideración de un tercer tipo de voz por parte de Nicómaco de Gerasa. Esta triple tipología de voz continua, interválica e intermedia fue tenida en cuenta en centurias posteriores, como lo prueban las partes cantadas, dialogadas y recitadas de composiciones ulteriores. Debemos a los antiguos teóricos griegos de la música las primeras reflexiones y teorizaciones sobre este arte y sus componentes, incluso aquellos más arraigados y casi inadvertidos hoy, como la voz y su movimiento.

\section{Notas}

* Doctora en Filología Clásica (Griego) por la Universidad de Murcia. Ha formado parte de varios Proyectos de Investigación destinados a la traducción, edición y comentario de varias obras de Benito Arias Montano, así como a la ampliación y consolidación de la Bibliotheca Montaniana. Actualmente acaba de culminar su participación en el Proyecto de Investigación Edición crítica, traducción y comentario filológico del "De nuptiis Philologiae et Mercurii” de Marciano Capela, en el que se ha encargado de la edición crítica, traducción y comentario del libro IV (Sobre la dialéctica) y acaba de comenzar su continuación, en el que está realizando el mismo trabajo en el libro IX (Sobre la harmónica). Su idéntico dominio del Latín, del Griego y de la Lengua Española, amén de sus conocimientos musicales, hace que cubra un amplio espectro académico, entre los que destacan sus publicaciones sobre la música en la Antigüedad y su pervivencia a lo largo de la Historia; la Lengua y la Historia de la Lengua Españolas; estudios sobre el léxico musical antiguo y su evolución al español actual; o la pervivencia del mundo clásico en la literatura española jesuítica del siglo XVIII. (fgdomene@uco.es)

1 En este trabajo se conservará la $h$ en harmonía y en sus derivados (salvo en enarmónico) ya que, al tratarse de un concepto eminentemente griego, es más adecuado mantener la forma etimológica para distinguir su uso en los autores helenos, para quienes esta voz se refería al "ajuste” o afinación de los grados de la escala, de la moderna noción de "armonía”, en cuanto que emisión simultánea de varios sonidos musicales.

2 Harris (1990: 47-48).

$\underline{3}$ El término música procede de $\mu$ ovбiкń, propiamente “el arte de las Musas”, formada con la raíz indoeuropea 
*men-. Así Michaelides (1978: s.v. «mousike»); Rodríguez Adrados (1980: 130-137); García-Morales (2004: 39,

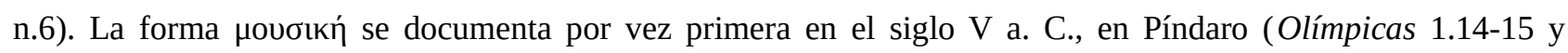
Fragmento 9), Heródoto (6.129) y Tucídides (3.104).

4 Arístides Quintiliano. 1.4; Alipio. 1 (Jan, 367.3-9); Anónimos de Bellermann 29, entre otros.

$\underline{5}$ De las muchas acepciones que de la palabra "voz" recoge el Diccionario de autoridades de 1739, solo nos interesan las siguientes: 1. "El fonido formado en la garganta y proferido en la boca del animal. Es del lat. vox [...] Quando à la voz, que por efta canal fale fe añade el inftrumento de la lengua, venimos à articular, y diftinguir effa voz...y defpués la lengua, hiriendo en las partes de la boca fufodicha como en las teclas, viene à articular la voz". 2. "Por extenfión fe llama el fonido, que forman algunas cofas inanimadas heridas del viento, ù hiriendo en él. Lat. vox". 8. "Se toma afsimifmo por el fonido natural, ù metal de ella, ù el modo con que fe oía de ella voluntariamente. Lat. vocis sonus". 9. "Se toma también por el modo, ù calidad de ella, en quanto fe percibe bien, ù no fe percibe, ò fuena, ù diffuena al oído”. 10. "En la Múfica es el fonido particular, ù tono correfpondiente á las notas, y claves, ù en la voz del que canta, ò en los inftrumentos. Lat. vox”. Del actual Diccionario de la Lengua, en cambio, únicamente tres acepciones tienen que ver nuestro estudio: 1. "Sonido que el aire expelido de los pulmones produce al salir de la laringe, haciendo que vibren las cuerdas vocales". 15. "Mús. Sonido particular o tono correspondiente a las notas y claves, en la voz de quien canta o en los instrumentos". 16. "Mús. Cada una de las líneas melódicas que forman una composición polifónica. Fuga a cuatro voces”.

6 Las escuelas aristoxénica y pitagórica son las dos corrientes de pensamiento musical más importantes de la Grecia antigua. Los aspectos musicales de tinte pitagórico se refieren, recuerdan o evocan aquellos ya tratados por eminentes figuras de la secta, como Filolao de Tarento (o de Crotona), Arquitas de Tarento, Trasilo o el propio Pitágoras. Estos versan, principalmente, sobre las proporciones de los intervalos musicales, concibiendo la música en la base del número: en este sentido la música es voũc. Frente a ellos, la postura aristoxénica pretende emular las consideraciones de Aristóxeno de Tarento, discípulo de Aristóteles y cuya obra harmónica es el primer tratado musical técnico conservado casi entero. Su forma de entender la música difiere de la pitagórica, dejando entrever procedimientos aristotélicos en su teoría del sonido como forma de movimiento del aire, por ejemplo. En este sentido, el método aristoxénico parte de la música en sí, tenida como espacio en el que han de hallarse las leyes que la rigen, sin necesidad de acudir a instancias externas, como las matemáticas: en este caso la música es ỏkoń.

$\underline{7}$ Fiel a la máxima mundum regunt numeri, los cuatro documentos que la tradición ha conservado del geraseno,

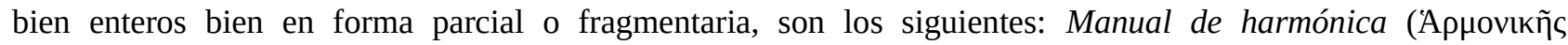

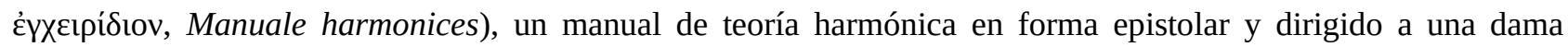

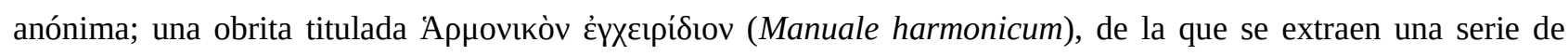
textos que componen los llamados Fragmentos de Nicómaco (Excerpta ex Nicomacho); Introducción a la

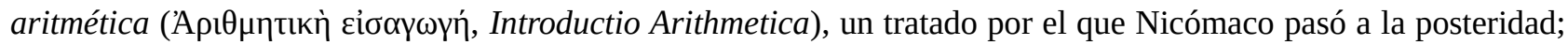

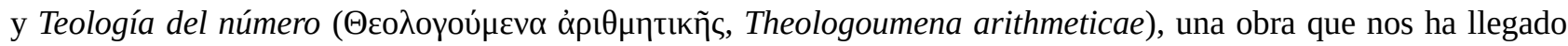
mutilada por transmisión indirecta, aunque enormemente valorada por tratarse de una de las mejores fuentes de información sobre el Neopitagorismo y sobre la propia filosofía nicomaquea.

8 Jan, 238.16-17.

9 La evolución en el tratamiento de las partes de la ciencia Harmónica por parte de los diversos autores que las nombran y estudian en sus respectivos tratados comienza en Aristóxeno de Tarento (Harmónica 2.35-38): géneros, intervalos, notas, escalas, tonos, modulación y melopeya. Tal ordenación de los elementos harmónicos es el reflejo de una expresión geométrica del espacio físico, donde no solo la nota recibe una preeminencia precisa, sino donde, además, es puesta en paralelo con un punto geométrico, según Gibson (2005: 144-145). La ordenación de Cleónides es ésta (Introducción a la harmónica 1; Jan, 179.6-8): notas, intervalos, géneros, escalas, tonos, modulación y melopeya. La enumeración de Arístides Quintiliano (1.5) es la que, paradójicamente, adoptaron musicólogos posteriores, como Alipio (1; Jan, 367.10-15), el texto de Anónimos de Bellermann (20) y Marciano 
Capela (9.938): notas, intervalos, escalas, géneros, tonos, modulación y melopeya. A diferencia de estos autores, Gaudencio ubica en último lugar los géneros (Introducción a la harmónica prefacio; Jan, 327.5-8): notas, intervalos, escalas, tonos, modulación, melopeya y géneros. El pseudoplutarqueo Sobre música (1142E) se limita a enumerarlas, sin entrar en mayores explicaciones: géneros, intervalos, escalas, notas, tonos y modulación.

10 Esta obra está dedicada a una dama anónima para cuya identificación se han postulado tres respuestas: una pitagórica, según la lista de miembros femeninos aceptada por los componentes de la secta (Jámblico. Vida Pitagórica 267.66-77, Deubner); una dama innominada; o la emperatriz Plotina Augusta, esposa del emperador Trajano. Cf. Ruelle (1880: 10, n. 2); D’Ooge-Robbins-Karpinski (1926: 76-77); McDermott (1977); Levin (1975: 17-18).

11 Locus voci et motus voci, éste entendido como el cambio de altura tonal y aquél como el registro en el que se

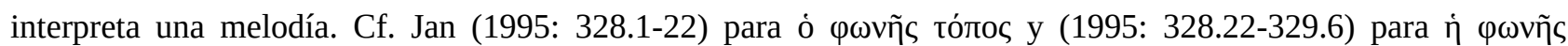
кívๆбıs.

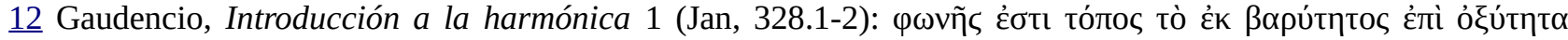

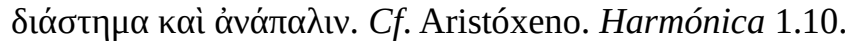

13 Introducción a la harmónica 1 (Jan, 328.22-24).

14 Introducción a la harmónica 1 (Jan, 328.24-25).

$\underline{15}$ Cf. la identificación de las regiones de la voz llevada a cabo por Arístides Quintiliano (1.12), Baquio (Introducción a la harmónica 43-44; Jan, 302.7-15) y Anónimos de Bellermann (63).

$\underline{16}$ Cf. Aristóxeno, Harmónica 1.3 y 1.8.

17 Mientras que Levin (1975: 46ss.; 1994: 42) apunta que el tratado de Nicómaco presta más atención a las teorías pitagóricas que al estudio de la ciencia harmónica, Barker (1989: 248, n. 3) habla de una reorganización de las ideas esenciales aristoxénicas y ulterior inserción en el sistema pitagórico. Zanoncelli (1990: 182, n. 1 al Cap. II), en cambio, parece disculpar a Nicómaco alegando que él no hace sino seguir una tendencia propia de la corriente neopitagórica que consiste en remontar a los orígenes más lejanos de la escuela los logros pitagóricos más destacados, tenidos como patrimonio cultural consolidado. Mathiesen (2000: 390-411), en fin, conjetura la posible adaptación de dichos preceptos pitagóricos con los aristoxénicos, pues es muy probable que el geraseno considerara como miembro de la escuela al tarentino o que éste desarrollara sus propias concepciones de una fuente pitagórica más antigua también conocida por Nicómaco. En este sentido, hay que tener en cuenta que el lugar de nacimiento de Aristóxeno, Tarento, fue un centro pitagórico y que su educación fue en la tradición propia de esta escuela.

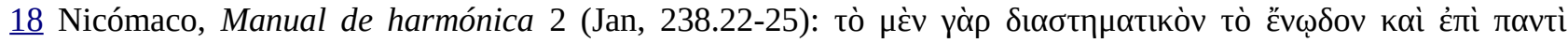

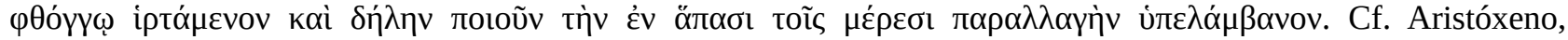
Harmónica 1.8-9.

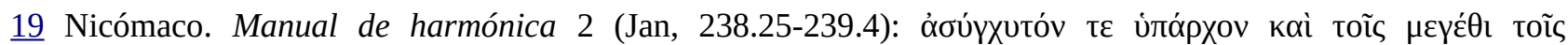

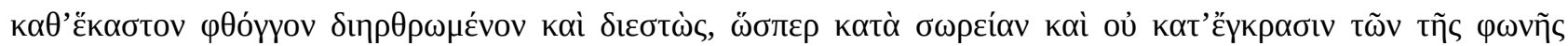

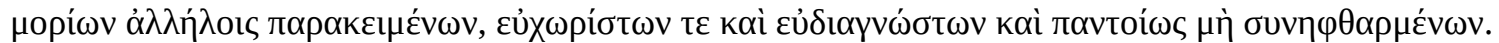

$\underline{20}$ Ruelle (1880: 172, n. 4) ve aquí una correspondencia en el arte de la pintura con la fusión de los colores.

21 Harmónica 1.8 y 1.10, donde Aristóxeno identifica dos movimientos de la voz: el continuo (бuvexńs), al que

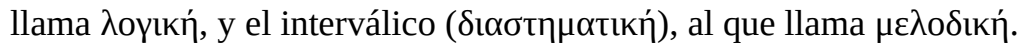

22 Cf. Cleónides, Introducción a la harmónica 2 (Jan, 180.11-181.11); Nicómaco, Manual de harmónica 2 (Jan, 238.16-240.26); y Ptolomeo, Música 6 (Jan, 413.2-4). 
23 Cf. Nicómaco, Manual de harmónica 2 (Jan, 239.8-12), que califica de manera semejante esta primera tipología de voz: conversación hablada. Es en la expresión "flujo sonoro" donde leemos la característica de esta

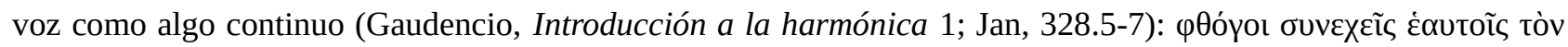

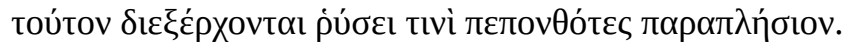

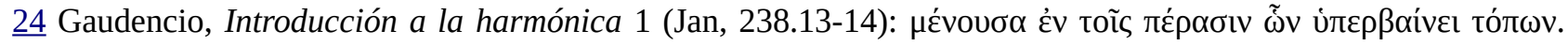
Según Ruelle (1895: 55, n. 6), estas palabras parecen ser una glosa marginal.

$\underline{25}$ La forma $\delta i \eta \rho \theta \rho \omega \mu \varepsilon ́ v o v$ se justifica por analogía con $\delta ı \eta \rho \rho \omega \mu \varepsilon ́ v \omega \varsigma$, pese a que las ediciones de Nicómaco dan

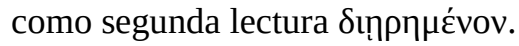

$\underline{26}$ Gaudencio, Introducción a la harmónica 1; Jan, 328.16-17.

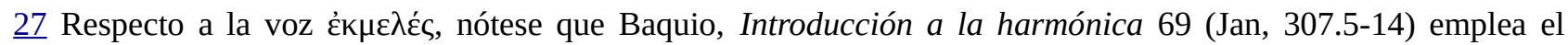

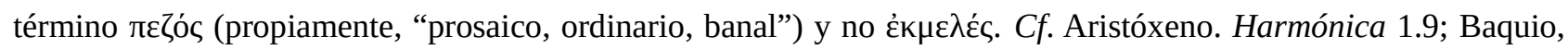

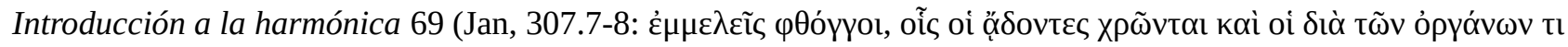

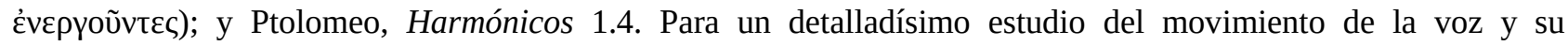
dificultad de distinción en una lengua como la griega, vid. Johnson (1899); Stanford (1967: 27ss.); Ax (1978 y 1986); Laver (1980 y 1991); Baken (1987).

$\underline{28}$ Sobre la diferencia entre intervalos “racionales” e “irracionales”, véase Michaelides (1978: s.v. “diastema”).

299 Aristóxeno, Rítmica 2.23.5-6; y Ptolomeo, Harmónicos 1.4.

30 Desde esta perspectiva, y junto con la leyenda del descubrimiento de Pitágoras de los sonidos y sus proporciones, Jan (1995: 319-320) hace manifiesta la aceptación gaudentiana de la escuela pitagórica. Cf. Zanoncelli (1990: 353, n. 2).

31 Aristóxeno, Harmónica 1.8-9.

32 Nicómaco, Manual de harmónica 2 (Jan, 239.13-17).

33 Harmónica 1.18.

34 Arístides Quintiliano 1. 4. Cf. Aristóxeno, Harmónica 1. 9.

$\underline{35}$ Para estas referencias, véase n. 15.

$\underline{36}$ Boecio, Sobre el fundamento de la música 1.12.

37 Marciano Capela 9.937.

38 Zanoncelli (1990: 183, n. 4 al Cap. 2).

39 Levin (1994: 39-44) en estas páginas establece una comparación del trabajo de Nicómaco y del estagirita concerniente al movimiento.

40 Ross (1936: 26-36) y Cherniss (1935: 385-86).

41 Las diversas traducciones de este término se dividen en aquéllas que lo interpretan como que "tiene o está compuesta de dos partes" (Meibom, 1652: 4; Ruelle, 1880: 173; Levin, 1994: 37), la que ve "dos tipos” de sonido vocal (Barker, 1989: 249) y, finalmente, la que atribuye a la voz humana "una doble función” (Zanoncelli, 1990: 145).

42 Aristóteles, Primeros analíticos 86a5-6 y Metafísica 999a26-29.

43 Platón, Filebo 17a-e; es interesante este pasaje porque, tomando como base el debate sobre lo uno y lo múltiple, del carácter ilimitado y unitario, demuestra la competencia o incompetencia de uno en música. 
44 Aristóteles, Física 211a1-7 y 212b5.

45 Platón, Timeo 36a-b. Esta concepción de un universo permanente y uniforme de lo cuantitativo se opone a la concepción aristoxénica de un universo variado de lo cualitativo. Cf. Garrido Domené (2013).

46 Harmónica 1.14. Este pasaje es la fuente principal de Nicómaco aquí. Téngase en cuenta, asimismo, la opinión de Teón de Esmirna al respecto (52-54).

47 Barker (1989: 249, n. 7).

48 Harmónica 1.3.

49 Harmónica 1.8.

$\underline{50}$ Comentario a los Harmónicos de Ptolomeo 85.

$\underline{51}$ Barker (1989: 249, n. 9).

$\underline{52}$ Ibidem.

$\underline{53}$ Nicómaco, Manual de harmónica 2 (Jan, 239.24-25).

$\underline{54}$ Harmónica 1.14.

55 Fragmento 4 (Jan, 274.11-20), donde se comparan las notas del registro grave y agudo con sonidos emitidos por animales. De la misma manera, lo dicho en estos pasajes por Nicómaco puede compararse con Ptolomeo, Harmónicos 1.4.

56 Barker (1989: 249-250, nn. 11-12). Más adelante, en el capítulo IV del tratado, Nicómaco subsanará dicha confusión estableciendo sus diferencias.

57 Arquitas, Fragmento 1 (ap. Porfirio. Comentario a los Harmónicos de Ptolomeo 56.5-57.27).

58 Como Rocconi (2003: 14 con n. 50) reconoce, estos dos términos indicarán, en toda la tratadística teórica, el acto de "bajar" o de "elevar" la entonación de las notas o sonidos musicales.

59 Harmónica 1.10. Cf. Baquio, Introducción a la harmónica 45 (Jan, 302.16-21) y Arístides Quintiliano. 1.5.

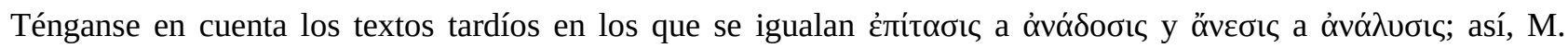
Brienio, Harmónica 3.308.19-20 (G. H. Jonker) y Anónimos de Bellermann 21 y 78, respectivamente.

\section{Bibliografía}

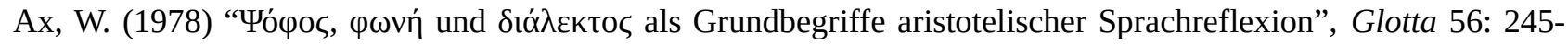
271.

Ax, W. (1986) Laut, Stimme und Sprache. Studien zu drei Grundbegriffen der antiken Sprachtheorie, Göttingen.

Baken, R. J. (1987) Clinical Measurement of Speech and Voice, Boston.

Barker, A. (1989) Greek Musical Writings. II. Harmonic and Acoustic Theory, Cambridge.

Cherniss, H. (1935) Aristotele’s Criticism of Presocratic Philosophy, Baltimore.

D’Ooge, M. L., Robbins, F. E., Karpinski, L. Ch. (1926) Nicomachus of Gerasa. Introductio to Arithmetic, New York.

García López, J. Morales Ortiz, A. (2004) Plutarco. Obras Morales y de Costumbres (Moralia). Obra completa. XIII. Sobre la música; Fragmentos, Madrid.

Garrido Domené, F. (2013) “El universo harmónico platónico (Ti. 35b-36b) según Nicómaco de Gerasa (Harm. 
VIII; pp. 250.3-252.2 Jan)”, Euphrosyne 41: 191-205.

Gibson, S. (2005) Aristoxenus of Tarentum and the Birth of Musicology, New York, London.

Harris, M. (1990) Our Kind, New York.

Jan, K. von (1995 [1895]) Musici scriptores Graeci. Aristoteles, Euclides, Nicomachus, Bacchius, Gaudentius, Alypius et melodiarum veterum quidquid exstat, Leipzig.

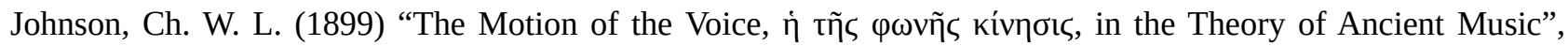
TAPhA 30: 42-55.

Laver, J. (1980) The Phonetic Description of Voice Quality, Cambridge.

Laver, J. (1991) The Grift of Speech: Papers in the Analysis of Speech and Voice, Edinburgh.

Levin, F. R. (1975) The Harmonics of Nicomachus and the Pythagorean Tradition, American Classical Studies, no. 1 University Park, The American Philological Association.

Levin, F. R. (1994) Nicomachus. Manual of Harmonics. Translation and Commentary, New York.

Mathiesen, Th. J. (2000) Apollo's Lyre. Greek Music and Music Theory in Antiquity and the Middle Ages, Lincoln, New York.

McDermott, W. (1977) “Plotina Augusta and Nicomachus of Gerasa”, Historia 26: 192-203.

Meibom, M. (1652) Antiquae musicae auctores septem. Graece et Latine. Amstelodami, I-II vol. Apud Ludovicum Elzevirium, Amsterdam.

Michaelides, S. (1978) The Music of Ancient Greece. An Encyclopaedia, London.

Rocconi, E. (2003) Le parole delle muse: la formazione del lessico tecnico musicale nella Grecia antica, Roma.

Rodríguez Adrados, F. (ed.) (1980) Lírica griega arcaica (Poemas corales y monódicos, 700-300 a. C.), Madrid.

Ross, W. A. (1936) Aristotele’s Physics: A Revised Text with Introduction and Commentary, Oxford.

Ruelle, Ch. E. (1880) Collection des autres grecs relatifs à la musique. II. Nicomaque de Gérase. Manuel d'Harmonique, Paris.

Stanford, W. B. (1967) The Sound of Greek: Studies in the Greek Theory and Practice of Euphony, Berkeley.

Zanoncelli, L. (1990) La manualistica musicale greca, Milano. 